\title{
MATHEMATICAL MODELING OF THE GRAPHITIZATION PROCESS APPLIED TO NODULAR CAST IRON PARTS
}

\author{
Elisabeta VASILESCU, Marian-Iulian NEACS,U \\ "Dunarea de Jos" University of Galati, Romania \\ e-mail: elisabeta.vasilescu@ugal.ro
}

\begin{abstract}
Used mainly in the construction of automobiles as a substitute for steel, or in the metallurgical industry, mainly in the manufacture of rolling mill cylinders, the mechanical properties of nodular cast iron depend largely on their structure, consisting of a ferritic metal mass, ferrite - pearlitic mass or pearlitic and graphite formations (graphite nodules) of maximum compactness.

The modification of the structure in the desired direction of use properties, possible by applying appropriate heat treatments, can be achieved in conditions of technical and economic efficiency by applying the optimal heat treatment variant, in which the technological parameters temperature - time have a decisive influence.

The paper summarizes some research results that aimed to establish the influence of annealing temperature and maintenance time to determine the optimal variant of graphite annealing heat treatment. Process modeling by statistical methods, indicated in the analysis of complex technological processes, has allowed, based on a preliminary experiment and then on the factorial experiment, the establishing of the degree of connection between the technological parameters of the process, as well as the technological parameter with the greatest influence on the process.
\end{abstract}

KEYWORDS: nodular graphite cast iron, annealing, ferritization, pearlitization, mechanical properties, mathematical modeling

\section{Introduction}

Ordinary nodular graphite cast irons are nonalloy cast irons having the following basic chemical composition: $3.4-3.9 \% \mathrm{C}$; $2.0-2.5 \% \mathrm{Si}$; $0.2-1.5 \% \mathrm{Mn}$; $\max .0 .08 \% \mathrm{P} ; \max .0 .03 \% \mathrm{~S}$.

Classification and characterization of nodular graphite cast iron taking into account mechanical properties include $[1,2]$ :

- cast iron with very high plasticity $(\mathrm{A} 5 \mathrm{~min}=$ $17 \%$ ); They are unalloyed cast irons with a very low content of manganese, phosphorus and sulphur (e.g. Fgn370-17) characterized by ferritic structure;

- cast iron with high plasticity (A5 = 12-17\%) still with ferritic structure but with a lower degree of purity (e.g. Fgn400-12);

- cast irons with medium plasticity, characterized by a ferrite-pearlitic structure (e.g. Fgn450-5 and Fgn500-7);

- cast irons with low plasticity (elongation at break is greater than or equal to $2 \%$ ) characterized by pearlitic structure (e.g. Fgn600-2 and Fgn700-2).
Higher values of mechanical strength correspond to cast irons with bainitic base metal mass, obtained either by isothermal hardening or by alloying [3]; At the same basic metal mass the ratio $\mathrm{Rp} 0,2$ / Rm is higher than for steels, the modulus of elasticity is in the range: $16500-18500 \mathrm{daN} / \mathrm{mm}^{2}$, and the fatigue strength, superior to cast iron with lamellar graphite, has values in the range: 12-28 $\mathrm{daN} / \mathrm{mm}^{2}$.

Nodular graphite cast irons are obtained by a process of modification of ordinary grey cast irons when mainly graphite spheroidization and primary carbide decomposition take place. The modification of the shape of graphite for spheroidization is done almost exclusively with magnesium or cerium (also called antigraphitizing modifiers), used in metallic form of pre-alloys, or in the form of salts. After the modification for the compaction of graphite, especially when these modifiers are used, the free cementite is also obtained in the structure, a constituent frequently present in the structure of nodular graphite cast iron in thin-walled parts. 
The removal of free cementite from the structure can be done either by annealing heat treatment or by a new modification (so-called postmodification) which is done with graphitizing modifiers (e.g. ferrosilicon, ferro-silicon-barium, silico-calcium-barium, silicocalcium-zirconium, etc.) introduced into the cast iron jet during its passage from the modification pot for spheroidisation of graphite into the casting pot. Graphite annealing is aimed at: decomposition of cementite and obtaining ferrite, decomposition of only free cementite or decomposition of only bound cementite [8].

The heat treatment of graphite annealing $[4,5]$ applied in order to decompose (graphitize) the primary cementite is carried out at a high temperature, close to the malleable annealing temperature, and the cooling is done with cooling rates depending on the desired structure, thus resulting in two variants of graphitization annealing (ferritization graphitization annealing or pearlitization graphitization annealing). Graphitization annealing with ferritization is performed in two subvariants: a variant in which the slow cooling takes place up to about $300{ }^{\circ} \mathrm{C}$ followed by air cooling, and the variant with pre-cooling in air up to about $650-700{ }^{\circ} \mathrm{C}$ followed by the transition to another oven heated to $760-770{ }^{\circ} \mathrm{C}$, in which a maintenance of $45-90 \mathrm{~min}$ is applied, for a ferrite - pearlitic or completely ferritic structure. Graphite annealing with perlitization involves cooling the parts in air (quiet or ventilated) to a temperature of about $450{ }^{\circ} \mathrm{C}$, after which they are placed in an oven at 500-550 ${ }^{\circ} \mathrm{C}$, maintaining a duration calculated with the practical rule "time and inch" followed from a cooling of $40-50{ }^{\circ} \mathrm{C} / \mathrm{h}$ up to $300{ }^{\circ} \mathrm{C}$ and then in the air. For the decomposition of ledeburitic cementite, the annealing must be done at temperatures of $900-950{ }^{\circ} \mathrm{C}$, for the decomposition of the secondary cementite at lower temperatures, and for the decomposition of eutectoid cementite at temperatures below point A1 (at about $700{ }^{\circ} \mathrm{C}$ ) [8].

\section{Experimental conditions}

The experiments were performed in laboratory conditions on grey cast iron samples. Different thermal regimes of graphitization annealing were applied, in different experimental variants and the influence of the basic technological parameters was followed, respectively the influence of the annealing temperature and the maintenance time at the annealing temperature on the physical-mechanical properties of the cast iron samples.

Figure 1 shows the heat cycle (heat treatment diagram) in the variant of graphite annealing with ferritization.

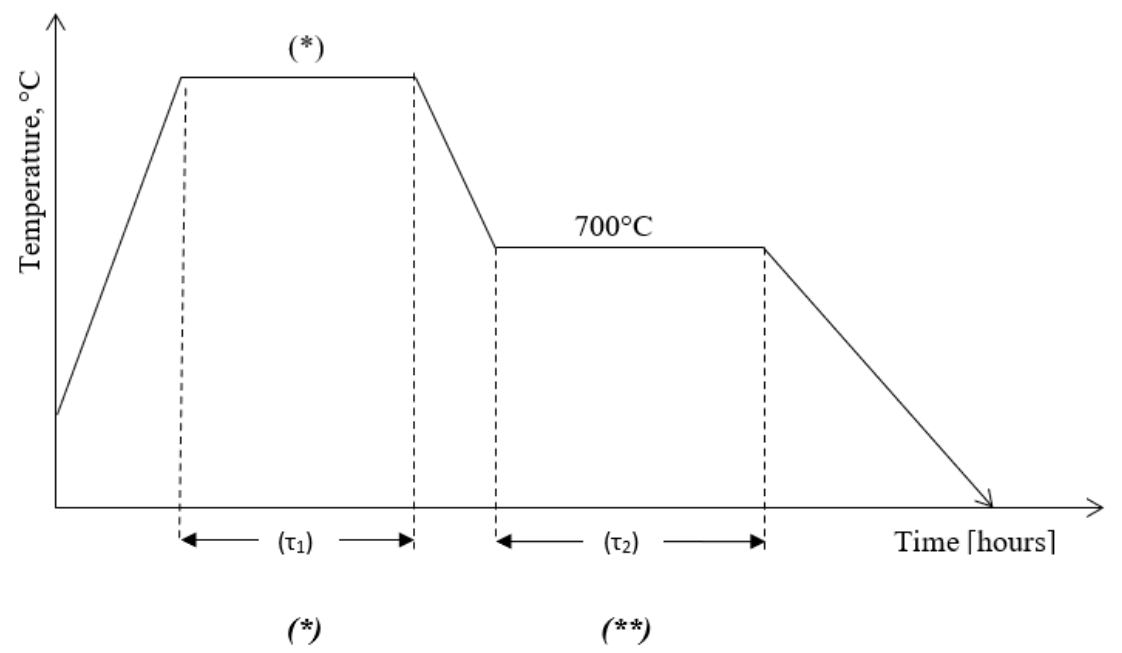

Fig. 1. Graphitization annealing (thermal cycle) (*) - annealing temperature: $980^{\circ} \mathrm{C}, 915{ }^{\circ} \mathrm{C}, 850^{\circ} \mathrm{C}$; $\left(\tau_{1}+\tau_{2}\right)$ - total holding time: 6 hours (regime 1), 8 hours (regime 2), 10 hours (regime 3 ), 12 hours (regime 4), 14 hours (regime 5); (**) - oven cooling

\section{Experimental results}

Changes in the values of mechanical properties for the experimental heat treatment regimes were analysed. The obtained results are expressed graphically in Figures 2-4.
Modeling in order to establish the equation (equations), respectively the mathematical model of the studied process, is performed based on a preliminary experiment, which provides a priori information, by establishing state variables and process parameters, determining the limits of existence and intervals of variation of factors (process 
THE ANNALS OF “DUNAREA DE JOS” UNIVERSITY OF GALATI

FASCICLE IX. METALLURGY AND MATERIALS SCIENCE

No. 4 - 2020, ISSN 2668-4748; e-ISSN 2668-4756

Article DOI: $\underline{\text { https://doi.org/10.35219/mms.2020.4.03 }}$

parameters), establishing the experimental error and the degree of connection between state variables and process parameters $[6,7]$. The actual modeling stage that is performed based on a classical or factorial experiment, and the processing of experimental data lead to the obtaining of the mathematical model, a model that describes with some approximation the real process.

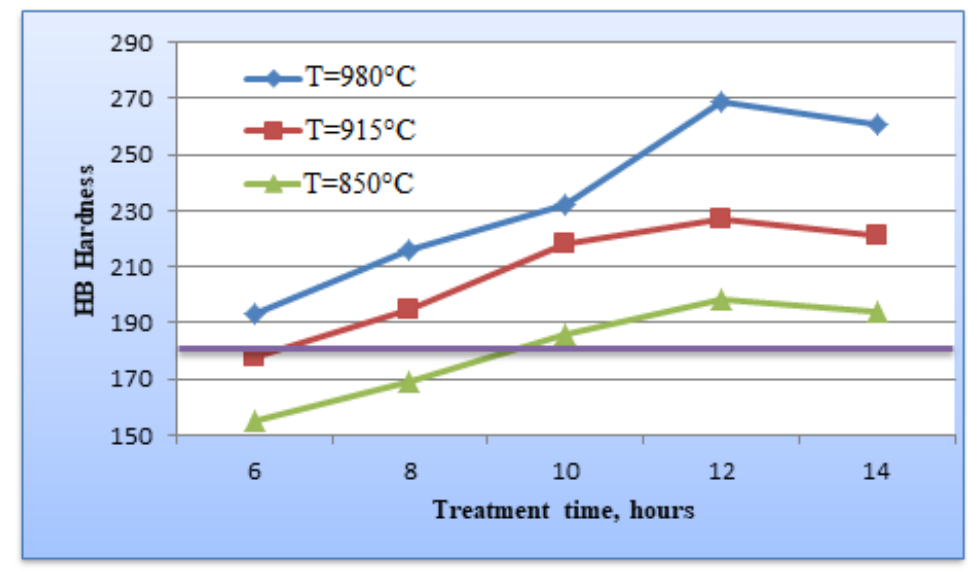

Fig. 2. Hardness variation $(H B)$ with graphite annealing temperature ${ }^{\circ} \mathrm{C}$

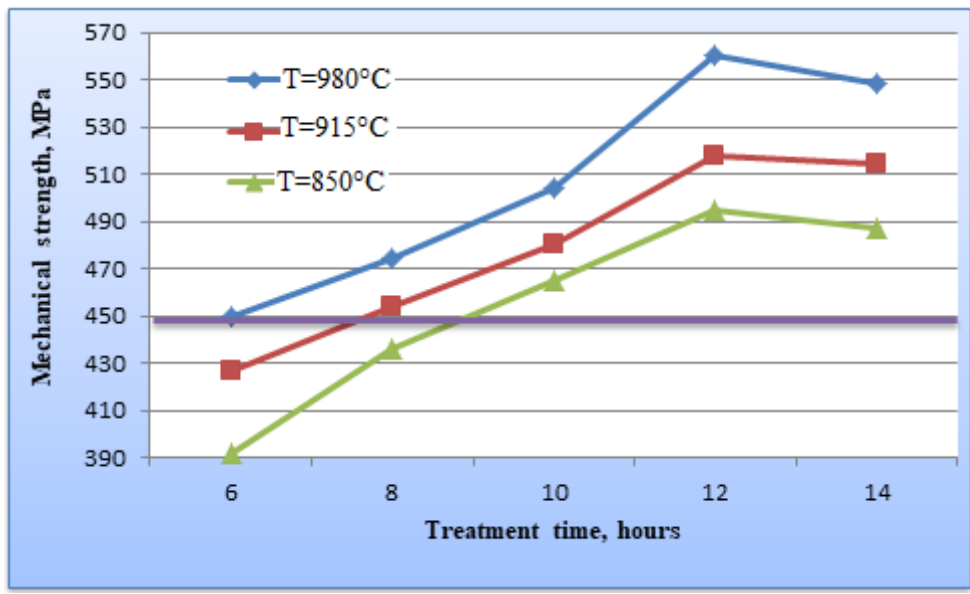

Fig. 3. Variation of mechanical tensile strength $(R m)$ with graphite annealing temperature maintenance time

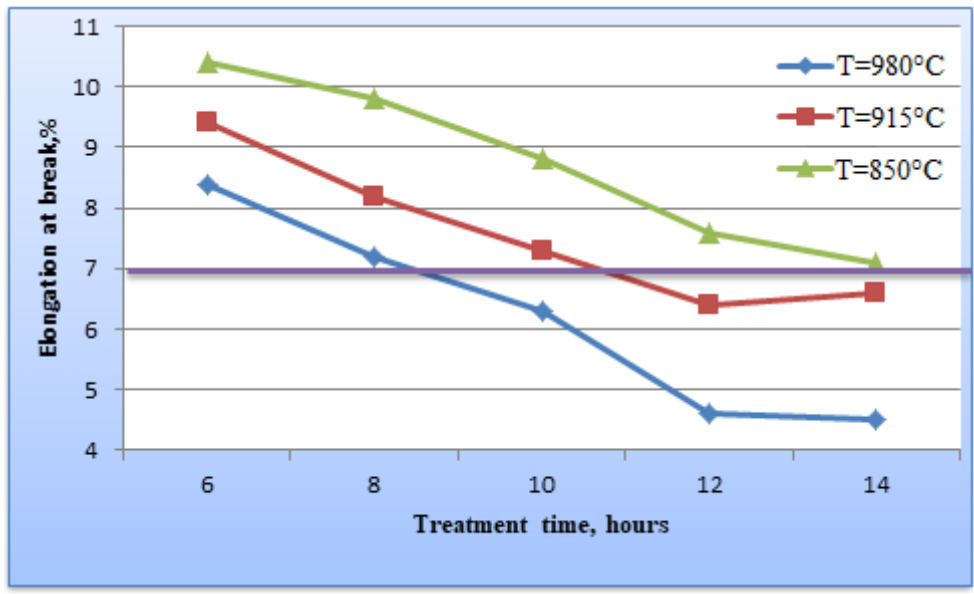

Fig. 4. Variation of elongation at break (A5) with graphite annealing temperature 
During the thermal processing, according to the adopted variant (graphitization annealing with ferritization), the mechanical properties are influenced by the variation of the treatment time and of the treatment temperature. Cooling rates are constant in the 15 experiments performed.

Mathematical modeling consists in creating a mathematical model that describes the variation of mechanical properties depending on the variation of treatment time and temperature according to the equation:

$$
\mathrm{Y}=\mathrm{c}_{0} \cdot \mathrm{x}_{0}+\mathrm{c}_{1} \cdot \mathrm{x}_{1}+\mathrm{c}_{2} \cdot \mathrm{x}_{2}+\mathrm{c}_{12} \cdot \mathrm{x}_{1} \cdot \mathrm{x}_{2}
$$

For this, it was established:

- higher level $(+1)$,

- basic level (0),

- lower level (-1) and
- the range of variation of the treatment process parameters.

Also, the correspondence of the coded parameters of the time and temperature and their natural parameters was established according to the formula:

$$
x_{1}=\frac{\tau-\tau_{0}}{\Delta \tau} \quad x_{2}=\frac{t-t_{0}}{\Delta t}
$$

where: $\tau$ - treatment time;

$\tau_{0}$ - treatment time at the basic level;

$t$ - treatment temperature;

$t_{0}$-treatment temperature at baseline.

The correspondence between the values of the factors expressed in natural units and those expressed in coded units is given in Table 1 .

Table 1. Correspondence between the values of the factors expressed in natural units and those expressed in coded units

\begin{tabular}{|c|c|c|c|c|}
\hline \multirow{2}{*}{ Factor } & \multicolumn{2}{|c|}{ Duration of the process } & \multicolumn{2}{c|}{ Annealing temperature } \\
\cline { 2 - 5 } & $\begin{array}{c}\text { Natural } \\
\text { units, in } \\
\text { hours }\end{array}$ & Coded values & $\begin{array}{c}\text { Natural } \\
\text { units, in } \\
\text { hours }\end{array}$ & Coded values \\
\hline $\begin{array}{c}\text { Basic } \\
\text { level }\end{array}$ & $\tau_{(0)}=10$ & $\frac{10-10}{4}=0$ & $\mathrm{t}_{0}=915^{\circ} \mathrm{C}$ & $\frac{915-915}{65}=0$ \\
\hline $\begin{array}{c}\text { Variation } \\
\text { range }\end{array}$ & $\Delta \tau=4$ & $\frac{14-10}{4}=+1$ & $\mathrm{t}_{+1}=980{ }^{\circ} \mathrm{C}$ & $\frac{980-915}{65}=+1$ \\
\hline $\begin{array}{c}\text { Higher } \\
\text { level }\end{array}$ & $\tau_{(+1)}=14$ & $\frac{6-10}{4}=-1$ & $\mathrm{t}_{1}=850^{\circ} \mathrm{C}$ & $\frac{915-850}{65}=-1$ \\
\hline $\begin{array}{c}\text { Lower } \\
\text { level }\end{array}$ & $\tau_{(-1)}=6$ & \multicolumn{2}{|c|}{} \\
\hline
\end{tabular}

In view of the coded representation of the experiment, the following annotations and symbols were used:

Independent variable:

- $\mathrm{X}_{1}$ - holding time, $\tau$, [hours];

- $\mathrm{X}_{2}$ - treatment temperature, $\mathrm{t},\left[{ }^{\circ} \mathrm{C}\right]$.

Dependent variables (parameters to be optimized):

- $\mathrm{Y}_{1}$ - breaking strength, Rm, [MPa];

- $\mathrm{Y}_{2}$ - Brinell hardness HB;
- $\mathrm{Y}_{3}$ - specific elongation at break, A5, [\%];

$\mathrm{Y}_{\mathrm{i}}$ values are expressed in natural units.

The mathematical regression equations are constructed for the 3 studied mechanical properties:

$\mathrm{Y}_{1}$ - Mechanical resistance;

$\mathrm{Y}_{2}$ - HB hardness and;

$\mathrm{Y}_{3}$ - Elongation at break, based on the experimental matrix.

The experimental matrix has the form:

\begin{tabular}{|c|c|c|c|c|c|c|c|}
\hline Nr. exp. & $\mathrm{X}_{0}$ & $\mathrm{X}_{1}$ & $\mathrm{X}_{2}$ & $\mathrm{X}_{1} \cdot \mathrm{X}_{2}$ & $\mathrm{Y}_{1}$ & $\mathrm{Y}_{2}$ & $\mathrm{Y}_{3}$ \\
\hline 1 & +1 & +1 & +1 & +1 & 548 & 261 & 4.5 \\
\hline 2 & +1 & -1 & +1 & -1 & 450 & 193 & 8.4 \\
\hline 3 & +1 & +1 & -1 & -1 & 514 & 221 & 6.1 \\
\hline 4 & +1 & -1 & -1 & +1 & 392 & 155 & 10.4 \\
\hline
\end{tabular}




\section{THE ANNALS OF “DUNAREA DE JOS” UNIVERSITY OF GALATI \\ FASCICLE IX. METALLURGY AND MATERIALS SCIENCE \\ $\mathrm{N}^{\circ} .4$ - 2020, ISSN 2668-4748; e-ISSN 2668-4756 \\ Article DOI: https://doi.org/10.35219/mms.2020.4.03}

After calculating the coefficients $\mathrm{c}_{0}, \mathrm{c}_{1}, \mathrm{c}_{2}$ and $\mathrm{c}_{1}$ - $\mathrm{c}_{2}$, the following equations expressed in coded quantities for the 3 properties resulted:

$$
\begin{gathered}
Y_{1}=476+55 \cdot x_{1}+23 \cdot x_{2}-6 \cdot x_{1} \cdot x_{2} \\
Y_{2}=207.5+33.5 \cdot x_{1}+19.5 \cdot x_{2}+0.5 \cdot x_{1} \cdot x_{2} \\
Y_{3}=7.35-2.075 \cdot x_{1}-0.9 \cdot x_{2}+0.1 \cdot x_{1} \cdot x_{2}
\end{gathered}
$$

By replacing the coded values with the natural ones and performing the calculations, the equations of the mathematical model for the studied (researched) thermal treatment process resulted are:

$$
\begin{aligned}
& Y_{1}=151.68+32.05 \cdot \tau+0.55 \cdot \mathrm{t}-0.02 \cdot \tau \cdot \mathrm{t} \\
& \mathrm{Y}_{2}=-132.4+6.54 \cdot \tau+0.28 \cdot \mathrm{t}+0.02 \cdot \tau \cdot \mathrm{t} \\
& \mathrm{Y}_{3}=27.1-0.784 \cdot \tau-0.016 \cdot \mathrm{t}+0.0003 \cdot \tau \cdot \mathrm{t}
\end{aligned}
$$

As can be seen from the analysis of the mathematical model equations, the mechanical properties are influenced more by the time factor than by the temperature factor because the coefficients of $\tau$ are higher than those of temperature.

\section{Conclusions}

The mechanical properties are influenced by the temperature and the duration of annealing, a significant influence being exerted by the maximum temperature reached at the heat treatment.

The mechanical strength properties (hardness, mechanical tensile strength) increase as the total holding time increases and reach a maximum at a holding time of 12 hours.

Increasing the total maintaining time above this value is no longer effective as the mechanical properties of strength begin to decrease and the mechanical properties of plasticity (elongation at break) remain constant.

\section{References}

[1]. Geru N., Chircă D., Bane M., Ripoșan I., ș.a., Materiale metalice. Structură, proprietăți, utilizări, Ed. Tehnică, București 1985.

[2]. Sofroni L., Ștefănescu D. M., Vincenz C., Fonta cu grafit nodular, Ed. Tehnică, București 1978, p. 5.

[3]. Ripoșan I., Sofroni L., Chișamera M., Fonta bainitică, Ed. Tehnică București, 1988.

[4]. Popescu N., Dumitrescu C., Munteanu A., Tratamente termice și prelucrări la cald, E. D. P. București, 1983.

[5]. Popescu N., Vitănescu C., Tehnologia tratamentelor termice, Ed. Tehnică, Bucureşti, 1974.

[6]. Taloi D., Bratu C., Florian E., Berceanu E., Optimizarea proceselor metalurgice, E. D. P., Bucureşti, 1983.

[7]. Taloi D., Optimizarea proceselor tehnologice. Aplicaţii în metalurgie, Editura Academiei, Bucureşti, 1987.

[8]. Geru N., Metalurgie fizică, E. D. P. București, 1981. 